\title{
Small-Animal PET/CT for Monitoring the Development and Response to Chemotherapy of Thymic Lymphoma in Trp53 ${ }^{-1-}$ Mice
}

Martin A. Walter ${ }^{1}$, Isabel J. Hildebrandt ${ }^{1}$, Katrin Hacke ${ }^{2}$, Adam L. Kesner ${ }^{1}$, Owen Kelly ${ }^{3}$, Gregory W. Lawson ${ }^{4}$, Michael E. Phelps ${ }^{1}$, Johannes Czernin ${ }^{1}$, Wolfgang A. Weber ${ }^{1,5}$, and Robert H. Schiestl ${ }^{3}$

${ }^{I}$ Department of Molecular and Medical Pharmacology, David Geffen School of Medicine, UCLA, Los Angeles, California; ${ }^{2}$ Department of Medicine, David Geffen School of Medicine, UCLA, Los Angeles, California; ${ }^{3}$ Department of Pathology, David Geffen School of Medicine, UCLA, Los Angeles, California; ${ }^{4}$ Division of Laboratory Animal Medicine, David Geffen School of Medicine, UCLA, Los Angeles, California; and ${ }^{5}$ Department of Nuclear Medicine, University Hospital, Freiburg, Germany

Transgenic mouse models of human cancers represent one of the most promising approaches to elucidate clinically relevant mechanisms of action and provide insights into the treatment efficacy of new antitumor drugs. The use of Trp53 transgenic mice (Trp53 knockout $\left[\operatorname{Trp53}^{-1-}\right]$ mice) for these kinds of studies is, so far, restricted by limitations in detecting developing tumors and the lack of noninvasive tools for monitoring tumor growth, progression, and treatment response. Methods: We hypothesized that quantitative small-animal PET with ${ }^{18} \mathrm{~F}-\mathrm{FDG}$ was able to detect the onset and location of tumor development, follow tumor progression, and monitor response to chemotherapy. To test these hypotheses, C57BL/6J Trp53-/- mice underwent longitudinal small-animal PET during lymphoma development and gemcitabine treatment. Trp53 wild-type $\left(\right.$ Trp5 $\left.3^{+/+}\right)$mice were used as controls, and histology after full necropsy served as the gold standard. Results: In Trp53 ${ }^{+/+}$ mice, the thymic standardized uptake value (SUV) did not exceed $1.0 \mathrm{~g} / \mathrm{mL}$, with decreasing ${ }^{18} \mathrm{~F}-\mathrm{FDG}$ uptake over time. Conversely, all $\operatorname{Trp} 53^{-1-}$ mice that developed thymic lymphoma showed increasing thymic glucose metabolism, with a mean SUV doubling time of $9.0 \mathrm{wk}$ (range, 6.0-17.5 wk). Using an SUV of $3.0 \mathrm{~g} / \mathrm{mL}$ as a criterion provided a sensitivity of $78 \%$ and a specificity of $100 \%$ for the detection of thymic lymphoma. Treatment monitoring with ${ }^{18} \mathrm{~F}-\mathrm{FDG}$ PET correctly identified all histologic responses and relapses to gemcitabine. Conclusion: ${ }^{18}$ F-FDG small-animal PET can be used to visualize onset and progression of thymic lymphomas in $\operatorname{Trp} 53^{-1-}$ mice and monitor response to chemotherapy. Thus, ${ }^{18} \mathrm{~F}-\mathrm{FDG}$ small-animal PET provides an in vivo means to assess intervention studies in the Trp53 transgenic mouse model.

Key Words: p53; knock-out mice; molecular imaging; metabolic imaging; treatment monitoring

J Nucl Med 2010; 51:1285-1292

DOI: 10.2967/jnumed.109.073585

Received Dec. 4, 2009; revision accepted Apr. 20, 2010.

For correspondence or reprints contact: Martin A. Walter, UCLA School of Medicine, University Hospital, Petersgraben 4, Basel, Switzerland 4031.

E-mail: m.a.walter@gmx.net

Guest Editor: Franz Buchegger, University Hospital of Lausanne

COPYRIGHT @ 2010 by the Society of Nuclear Medicine, Inc.
$\mathbf{M}$ urine cancer models are important tools for oncologic research. However, currently used transplantation models in immunodeficient mice are not an optimal model for tumors in humans, because subcutaneous transplantation of malignant cells initiates tumors far distant from the original site of the tumor, a lack of an intact immune system in these mice could alter pathophysiologic characteristics of the tumor, and tumors that emerge from long-term cultured cell lines might not display the natural characteristics of the human tumor. In contrast, transgenic mouse models have been proven to be an important model to help elucidate clinically relevant mechanisms of action and provide insights into treatment efficacy of new antitumor drugs $(1,2)$.

The tumor suppressor $p 53$ is the most frequently mutated gene in human cancers, including a wide variety of solid (3) and hematologic malignancies (4). Therefore, p53 has emerged as an important target for novel cancer therapies. As a transcription factor, p53 is involved in regulating the cell cycle, apoptosis, and senescence; facilitating DNA repair; and antagonizing angiogenesis (5). Clinical studies have demonstrated that $p 53$ inactivation is associated with rapid disease progression (6-10) and poor clinical outcome (11) in several lymphoma types.

The Trp53 knockout $\left(\operatorname{Trp} 53^{-/-}\right)$mouse was the first tumor-suppressor knockout model reported (12). Homologous recombination was used to disrupt the $\operatorname{Trp} 53$ gene by replacing both intron 4 and exon 5 (12), exon 2 (13), or exons 2-6 $(14,15)$ to generate Trp53--- mice $(16)$. These mice are highly susceptible to the formation of a variety of tumors. The most common tumor type is the thymic lymphoma, which occurs in about $70 \%$ of the animals (12). $\operatorname{Trp} 53^{-/-}$mice have been widely used to study the role of $p 53$ in the biology of lymphomas (17-20). The use of transgenic $\operatorname{Trp} 53^{-1-}$ models for intervention studies, however, has been limited by the lack of noninvasive tools for monitoring lymphoma development and treatment response in living mice. 


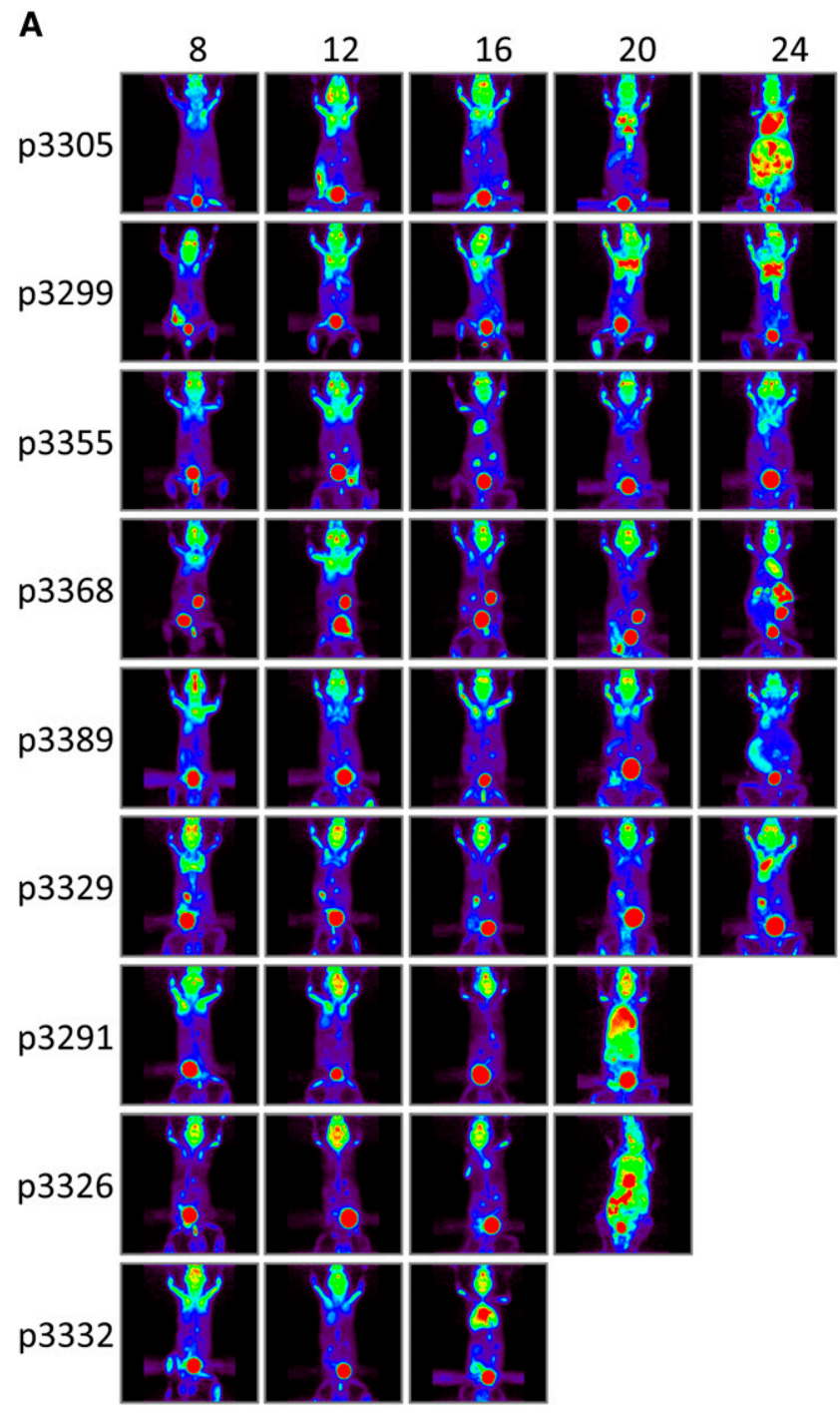

B

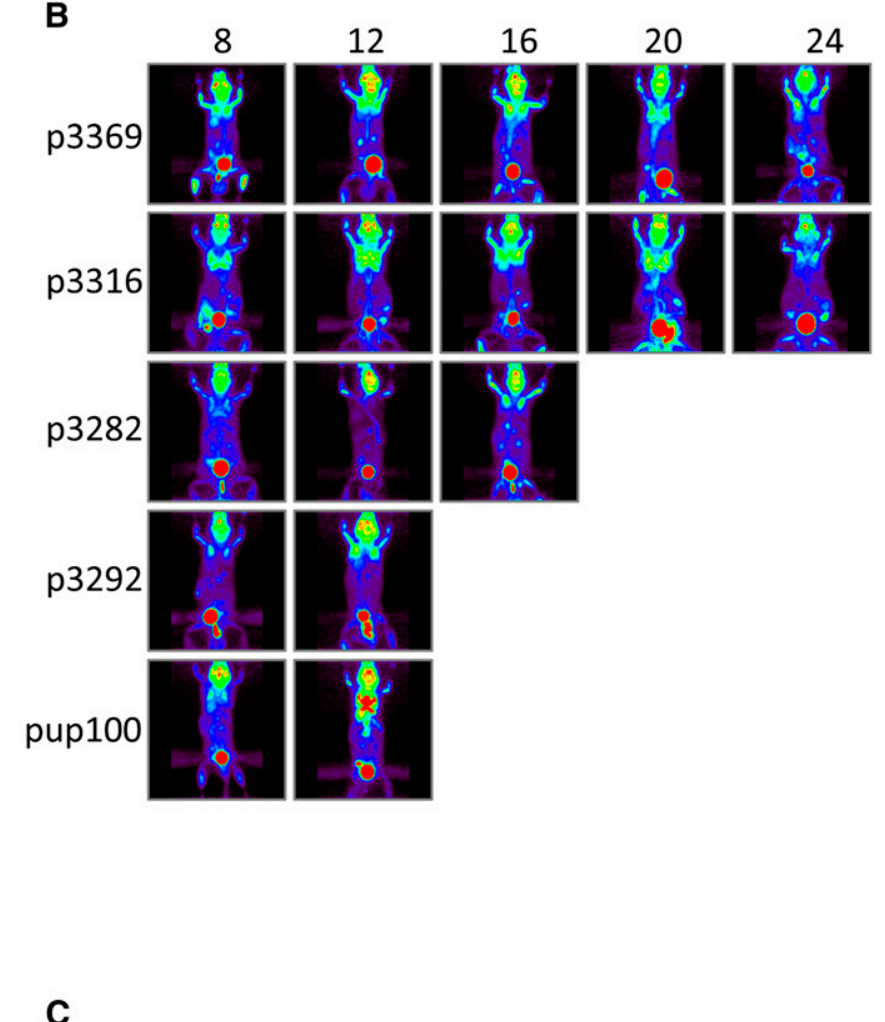

C

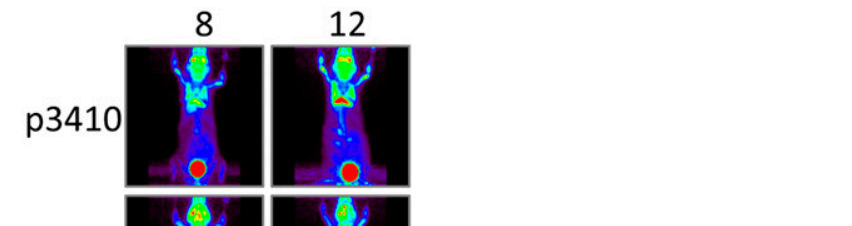

p3465

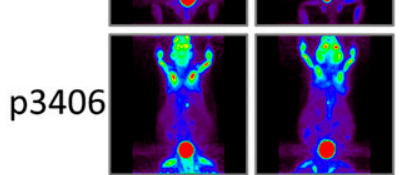

D

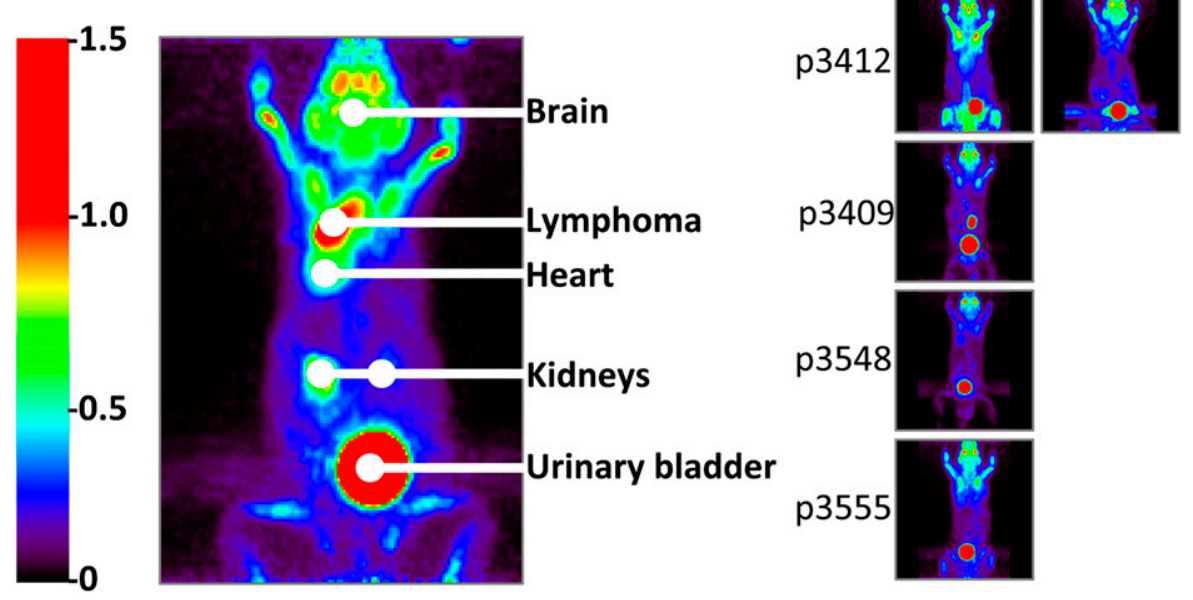


The gold standard for phenotypic analysis in murine cancer models is histology, which requires tissue removal and thereby precludes longitudinal investigations in the same animal, including treatment studies. Caliper measurements, on the other hand, offer longitudinal estimation of growth in palpable tumors and thereby exclude most orthotopic tumor models, such as the thymic lymphomas developing in $\operatorname{Trp} 53^{-/-}$mice.

PET is an imaging technique that allows for the noninvasive visualization and quantification of metabolic processes in vivo. PET provides the means to measure the rates of biologic processes using molecules labeled with positron-emitting radioisotopes. The most commonly used labeled PET probe is ${ }^{18} \mathrm{~F}-\mathrm{FDG}$, which allows imaging of alterations in glycolysis associated with malignant transformations in cells. Hodgkin lymphoma and most subtypes of indolent and aggressive non-Hodgkin lymphoma have markedly increased rates of glycolysis and, accordingly, ${ }^{18}$ F-FDG PET shows a high sensitivity and specificity in the initial diagnosis and staging of these malignancies (21). Furthermore, ${ }^{18} \mathrm{~F}-\mathrm{FDG}$ PET allows for the early monitoring of treatment responses that induce changes in glycolysis and thereby the prediction of treatment responses in patients undergoing systemic chemotherapy (22). In addition, recent studies have indicated that loss of $p 53$ function alters cellular glucose metabolism, further supporting the use of ${ }^{18} \mathrm{~F}$-FDG PET in the $\operatorname{Trp} 53^{-/-}$model $(23,24) .{ }^{18} \mathrm{~F}-$ FDG PET has been used to monitor tumor progression in breast cancer xenografts (25), but to our knowledge there are no data on the use of ${ }^{18} \mathrm{~F}$-FDG PET for monitoring malignant transformation and tumor progression in orthotopic murine tumor models.

Herein we describe the use of ${ }^{18} \mathrm{~F}-\mathrm{FDG}$ PET for monitoring development and treatment response of orthotopic lymphomas in the $\operatorname{Trp} 53^{-/-}$mouse model. We hypothesized that PET could allow the noninvasive monitoring of lymphoma activity in Trp53-deficient mice and would permit early treatment monitoring. We report that ${ }^{18} \mathrm{~F}$-FDG PET can accurately assess the onset of thymic lymphomas, provide a readout of the proliferation fraction and progression, and determine response and relapse in systemic chemotherapy of $\operatorname{Trp} 53^{-/-}$mice.

\section{MATERIALS AND METHODS}

\section{Animals \\ p53 knockout mice originally developed by Donehower et al. (12) were purchased from GenPharm. The mice were crossed into a C57BL/6Jpun/pun genetic background. The genotype of the Trp53--- mice was determined by polymerase chain reaction using the primer}

pair $p 53$ forward ( $5^{\prime}$-GTG TTT CAT TAG TTC CCC CAC CTT TGA C- $\left.3^{\prime}\right)$ and $p 53$ reverse ( $5^{\prime}$-ATG GGA GGC TGC CAG TCC), and p53-neo (5'-CGC ATC GCC TTC TAT CGC CT-3'). Polymerase chain reaction was performed for 35 cycles of $94^{\circ} \mathrm{C}$ for $30 \mathrm{~s}, 63^{\circ} \mathrm{C}$ for $2 \mathrm{~min} 30 \mathrm{sec}$, and $72^{\circ} \mathrm{C}$ for $7 \mathrm{~min}$.

Mice were bred and maintained in a specific pathogen-free animal facility with a 12 -h light and dark cycle, at $22^{\circ} \mathrm{C} \pm 1{ }^{\circ} \mathrm{C}$ and a relative humidity of $40 \%-70 \%$. Food and water were supplied ad libitum. Cages and water bottles were changed once a week throughout the study. All animal manipulations were conducted with sterile techniques in accordance with the Guide for the Care and Use of Laboratory (26) and the guidelines of the University of California at Los Angeles (UCLA) Animal Research Committee.

\section{Small-Animal PET/CT}

Small-animal PET/CT scans were obtained under standardized conditions using the microPET Focus 220 scanner (Siemens Preclinical Solutions) and MicroCAT II scanner (Siemens Preclinical Solutions). ${ }^{18} \mathrm{~F}-\mathrm{FDG}$ production and quality control were performed by the UCLA cyclotron facility. Mice were fasted for $12 \mathrm{~h}$ before ${ }^{18} \mathrm{~F}-\mathrm{FDG}$ injection but allowed free access to water. For ${ }^{18} \mathrm{~F}$-FDG injection and imaging, mice were anesthetized using $2 \%$ isoflurane. The animals were then intraperitoneally injected with 7.4 MBq $(200 \mu \mathrm{Ci})$ of ${ }^{18} \mathrm{~F}-\mathrm{FDG}$, allowed to regain consciousness, and kept at $37^{\circ} \mathrm{C}$ until imaging. Imaging was started at $60 \mathrm{~min}$ after an intraperitoneal injection. Mice were imaged in a chamber that minimized positioning errors between PET and CT to less than $1 \mathrm{~mm}$ (27). Image acquisition time was $10 \mathrm{~min}$. Images were reconstructed by filtered backprojection, using a ramp filter with a cutoff frequency of 0.5 Nyquist. Image counts per pixel per second were calibrated to activity concentrations $(\mathrm{Bq} / \mathrm{mL})$ by measuring a $3.5-\mathrm{cm}$ cylinder phantom filled with a known concentration of ${ }^{18} \mathrm{~F}-\mathrm{FDG}$. Immediately after the PET scan, the mice underwent a 7-min micro-CT scan using routine image-acquisition variables $(70 \mathrm{kVp}, 90 \mathrm{mAs}$, with 2-mm aluminum filters).

\section{Image Analysis}

Images were analyzed using AMIDE software (28). Spheric regions of interest ( $2 \mathrm{~mm}$ in diameter) were placed in regions of focal ${ }^{18} \mathrm{~F}$-FDG uptake not explained by the physiologic distribution of ${ }^{18} \mathrm{~F}-\mathrm{FDG}$ in mice. All regions of interest were defined on fused PET/CT images to ensure reproducible positioning. The intensity of ${ }^{18} \mathrm{~F}$-FDG uptake was quantified using the mean standardized uptake value (SUV) (tissue radioactivity concentration/ [decay-corrected injected activity/body weight]; expressed in $\mathrm{g} / \mathrm{mL}$ ). Maximum-intensity-projection images were also generated to provide a whole-body overview of disease extension.

\section{Gemcitabine (Gemzar; Eli Lilly Co.) In Vivo \\ Treatment Model}

To explore the ability of ${ }^{18}$ F-FDG PET as a monitoring tool in systemic chemotherapy, we treated $\operatorname{Tr} p 53^{-/-}$mice with tumors detected by ${ }^{18}$ F-FDG PET with gemcitabine. Stock solutions of

FIGURE 1. General study layout. Eight-week-old Trp53-1- mice that developed (A) or did not develop (B) thymic lymphoma were subjected to serial PET/CT scans until age of 24 wk or until death. For control, Trp53 ${ }^{+/+}$mice $(C)$ were scanned with same PET/CT protocol per scan. Each row of images corresponds to a given animal, and each column corresponds to time point for imaging. Intensity scale displays color scale representing uptake relative to brain. Example image (D) represents enlarged view of study mouse, showing different uptake levels in organs. 


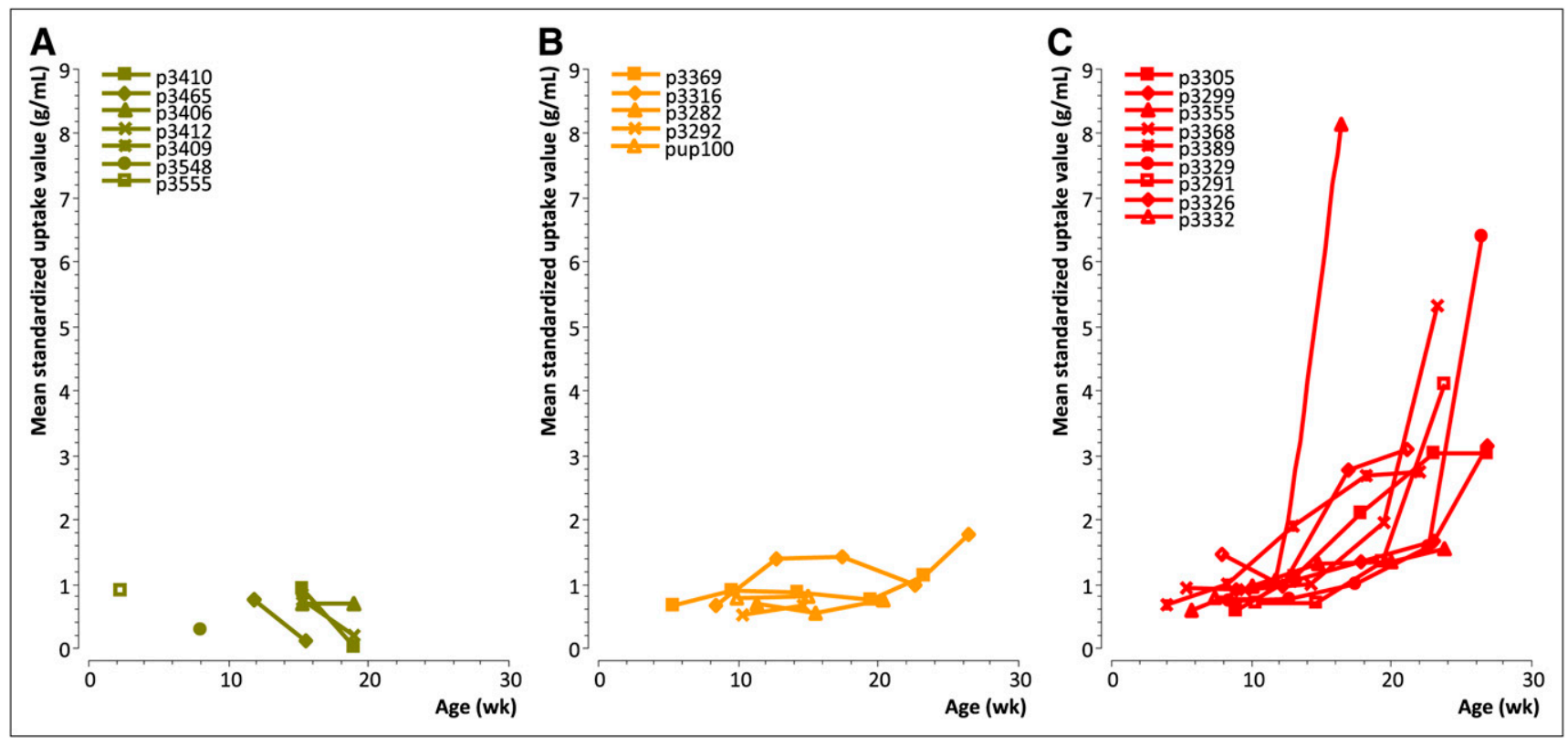

FIGURE 2. Serial thymic ${ }^{18} \mathrm{~F}-\mathrm{FDG}$ uptake in $\operatorname{Trp} 53^{+/+}$mice (A), Trp53-/- mice that did not develop thymic lymphoma (B), and $\operatorname{Trp53}^{-1-}$ mice that developed thymic lymphoma (C). SUV higher than $3 \mathrm{~g} / \mathrm{mL}$ was found only in mice with thymic lymphoma, and SUV below $3 \mathrm{~g} / \mathrm{mL}$ correctly ruled out thymic lymphoma in 5 of 7 mice.

$10 \mathrm{mg}$ of gemcitabine per milliliter were prepared in $0.9 \% \mathrm{NaCl}$. Mice received an intraperitoneal injection of 100-200 $\mu \mathrm{L}$ of gemcitabine at a dose of $60 \mathrm{mg} / \mathrm{kg}$ (starting at day 0 ) every $4 \mathrm{~d}$ and were sacrificed after $12-24 \mathrm{~d}$. Serial ${ }^{18}$ F-FDG small-animal PET was performed on all treated mice every $4 \mathrm{~d}$ to measure changes in glucose use in selected target tissues. Mice were weighed every $4 \mathrm{~d}$ and examined daily for signs of toxicity (weight loss $>15 \%$; reluctance to move, eat, or drink; hunched posture; ruffled coat or
FIGURE 3. Correlation of PET/CT with histology. Regions of interest (circles) were placed on serial sections of coronal and sagittal PET/CT images (A) to compute ${ }^{18} \mathrm{~F}-\mathrm{FDG}$ uptake in selected organs. Uptake was followed over study period (B). Each mouse was sacrificed after last scan to obtain histology from organs of interest (C). Mouse p3355 developed thymic lymphoma with low ${ }^{18} \mathrm{~F}-\mathrm{FDG}$ uptake, with mitotic index of 11.6. In contrast, mouse p3329 developed thymic lymphoma with high ${ }^{18} \mathrm{~F}-\mathrm{FDG}$ uptake, with mitotic index of 77.2. Mouse p3389 also developed lymphoma in spleen, with $60 \%$ organ involvement.

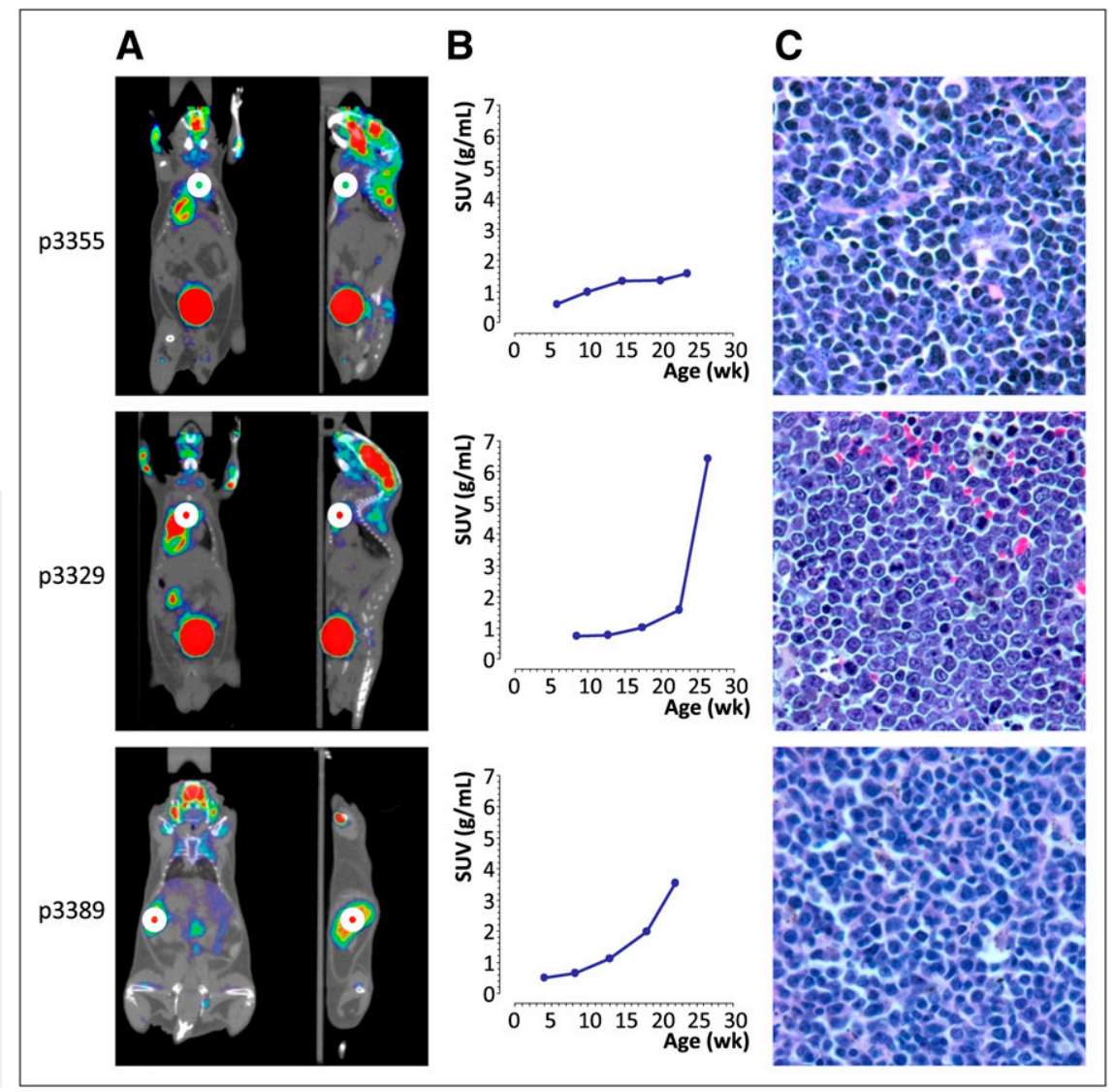


fur loss). When signs of toxicity that did not resolve within $24 \mathrm{~h}$ were observed, mice were euthanized. After 12-24 d of gemcitabine treatment, all animals were sacrificed after a final scan and were fixed in $10 \%$ buffered formalin. Twenty-four hours later, the formalin-preserved animals were transferred for full necropsy and histologic examination.

\section{Histopathology and Mitotic Index}

All necropsies and histologic examinations were performed by a veterinary pathologist (UCLA Division of Laboratory Animal Medicine Diagnostic Service Laboratory) unaware of the genotype data, treatment information, and PET results. Tissues of all thoracic and abdominal organs were histologically examined. The selected tissues were sliced, placed in tissue cassettes, and submitted for paraffin-embedding and sectioning. Each paraffin block was sectioned to $4 \mu \mathrm{m}$, and routine Mayer hematoxylin and eosin staining was performed. Each tissue was examined by light microscopy, and all pathology was recorded.

The mitotic index was based on the most mitotically active areas. Five fields were counted, and the mean number of mitotic figures per $\times 40$ magnification fields was determined.

\section{Statistical Analyses}

Discrete variables were summarized by counts and percentages and continuous variables by their medians and ranges, unless stated otherwise. The ${ }^{18}$ F-FDG SUV doubling time in thymic lymphomas was assessed using an exponential growth equation. The association of mitotic indices and SUVs was analyzed using Spearman correlation. All $P$ values were 2 -sided, and $P$ values less than 0.05 were considered to be statistically significant. Data were analyzed using Statistica software (version 6.0; StatSoft) for Windows (Microsoft).

\section{RESULTS}

${ }^{18}$ F-FDG PET Can Accurately Assess Onset of Thymic Lymphomas in Trp53-/- Mice

Twenty-one mice underwent serial ${ }^{18} \mathrm{~F}$-FDG PET for the diagnostic part of this study (14 $\operatorname{Trp} 53^{-1-}$ mice and $7 \operatorname{Trp} 53$ wild-type $\left[\operatorname{Trp} 53^{+/+}\right]$littermates as controls; mean age \pm $\mathrm{SD}, 9.3 \pm 3.8 \mathrm{wk})$. Figures $1 \mathrm{~A}-1 \mathrm{C}$ show the general study layout, and Figure 1D shows a representative image, with areas of high metabolic activity in the thymic lymphoma, brain, and heart and in ${ }^{18} \mathrm{~F}-\mathrm{FDG}$ excretion pathways such as the kidneys and urinary bladder.

Nine of $14 \operatorname{Trp}^{-1-}$ mice $(64.2 \%)$ developed thymic lymphomas; lymphomas were excluded by histology in 5 Trp53 ${ }^{-1-}$ mice (35.8\%). In Trp53 $3^{+/+}$mice, ${ }^{18}$ F-FDG PET measured thymic SUVs exclusively below $1 \mathrm{~g} / \mathrm{mL}$ (Fig. 2A). Furthermore, serial imaging revealed that SUVs in the thymus of the Trp53 $3^{+/+}$mice were decreasing around week 16 .

All $\operatorname{Trp} 53^{-/}$mice in which a lymphoma was excluded by histology displayed thymic SUVs below $3 \mathrm{~g} / \mathrm{mL}$ over the entire observation period (Fig. 2B). Serial PET measurements revealed no decrease in glucose metabolism over time in the $\operatorname{Trp} 53^{-/}$mice, compared with the $\operatorname{Trp} 53^{+/+}$mice.

All $\operatorname{Trp}_{53}{ }^{-/}$mice that developed thymic lymphoma showed increasing thymic glucose metabolism over time. The earliest lymphoma measurable by PET was found in a 16-wk-old mouse using an SUV of more than $3 \mathrm{~g} / \mathrm{mL}$ as a criterion of lymphoma development. The thymic lymphomas showed a mean SUV doubling time of 9.0 wk (range, 6.0-17.5 wk; Fig. 2C), and 7 of these lymphomas displayed SUVs exceeding the threshold of $3 \mathrm{~g} / \mathrm{mL}$ (sensitivity, 77.8\%; specificity, $100 \%$ ).

\section{${ }^{18}$ F-FDG PET Provides Readout of Proliferation \\ Fraction in Trp53 $3^{-/-}$Mice}

High rates of glycolysis, as seen with high ${ }^{18} \mathrm{~F}-\mathrm{FDG}$ uptake values, were generally found in highly proliferative thymic lymphomas (Figs. 3A-3C). At necropsy, the thymic lymphomas from the diagnostic (PET-positive, $n=5$; PETnegative, $n=2$ ) and therapeutic parts of this study (in remission, $n=3$; in relapse, $n=1$ ) showed a median mitotic index of 13.2 (range, 0-77.2), and the median thymic SUV of the corresponding ${ }^{18}$ F-FDG PET scan was 3.1 $\mathrm{g} / \mathrm{mL}$ (range, 0.5-6.4 g/mL). The Spearman test revealed a positive linear correlation between mitotic index and SUV ( $P=0.002, r=0.83$, Fig. 4). Three Trp53 ${ }^{-/-}$mice developed histologically verified secondary lymphoma lesions in the spleen. These lymphomas could also be monitored via serial ${ }^{18}$ F-FDG PET (Fig. 3). Furthermore, 3 Trp53-/mice developed malignancies other than lymphomas (1 intestinal carcinoma, 1 hemangiosarcoma, and 1 epididymal cancer). These tumors were also visualized on the ${ }^{18} \mathrm{~F}$ FDG PET scan.

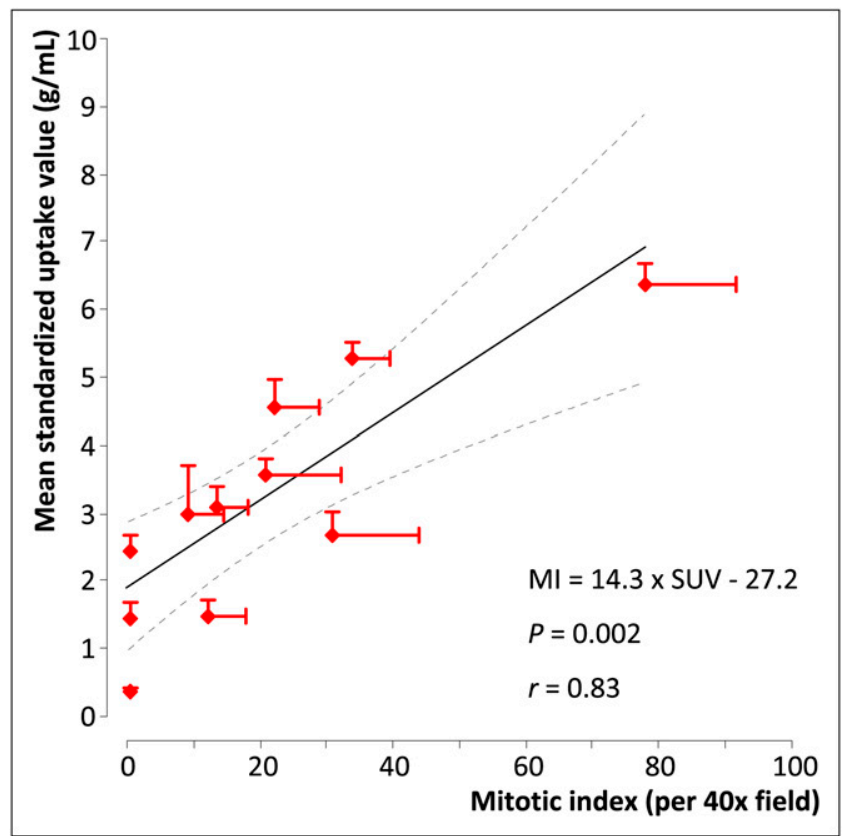

FIGURE 4. Correlation of ${ }^{18} \mathrm{~F}-\mathrm{FDG}$ uptake and proliferation. Thymus SUV in final ${ }^{18} \mathrm{~F}$-FDG PET/CT scan and mitotic index of thymic lymphoma were determined in 11 mice and displayed linear correlation, with $r=0.83$ (error bars indicate $[x$-axis] SD of 5 independently counted mitotic indices and [y-axis] SD of mean SUV within 1 selected region of interest). All SUVs were determined on last scan before sacrifice. Dashed lines represent 95\% confidence intervals for trend line of correlation. $\mathrm{MI}=$ mitotic index. 


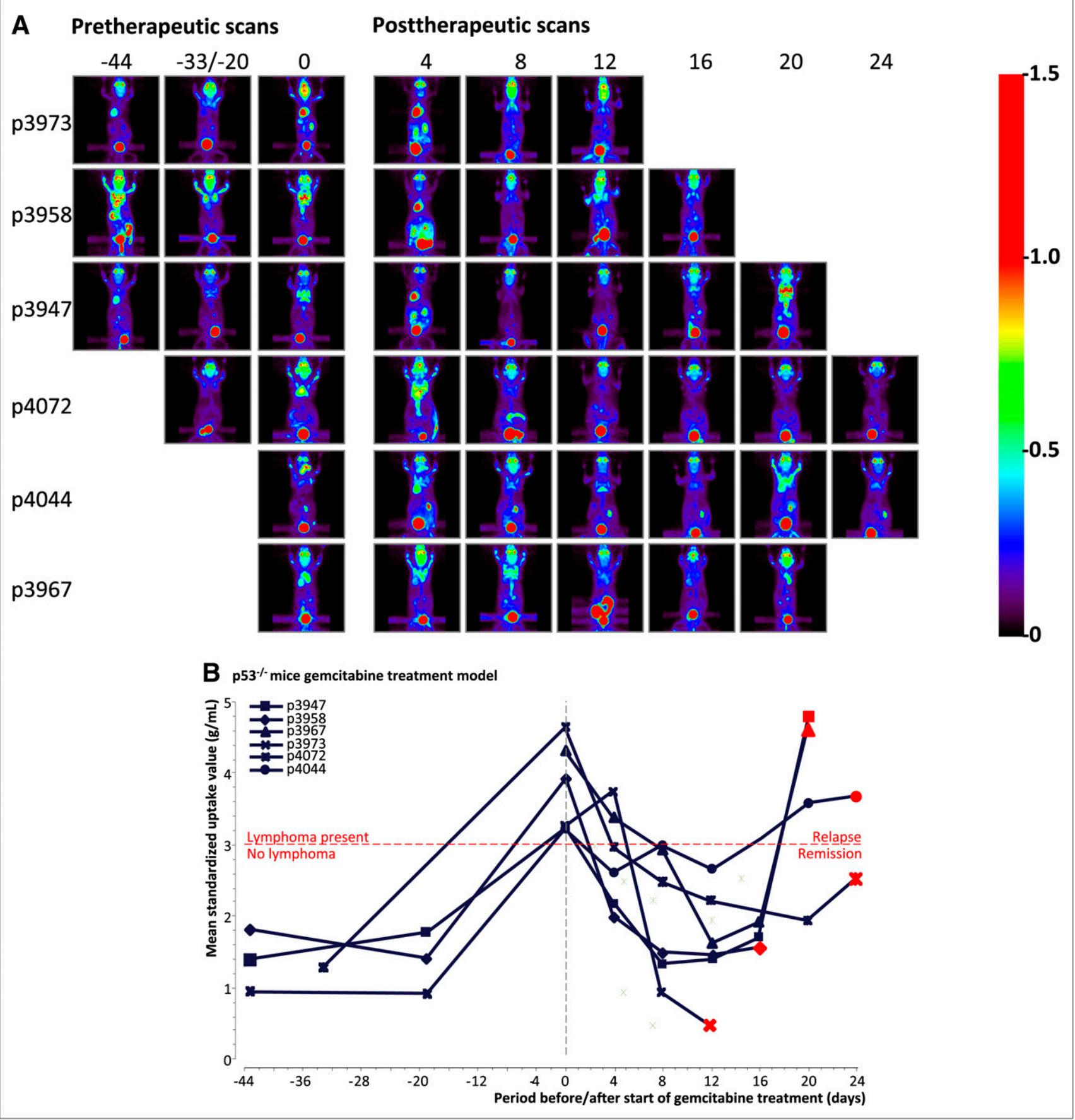

FIGURE 5. Gemcitabine treatment model. Thirteen Trp53-1- mice were serially scanned; 6 of these mice developed thymic SUVs exceeding $3 \mathrm{~g} / \mathrm{mL}$. These 6 mice were scanned and treated intraperitoneally with $60 \mathrm{mg}$ of gemcitabine per kilogram every $4 \mathrm{~d}$ and were sacrificed at 12-24 d after initialization of treatment (A). Gemcitabine treatment resulted in complete remissions at days 12 and 16 and local recurrence under therapy at days 20 and 24 of treatment, as verified by histology. Accordingly, ${ }^{18} \mathrm{~F}-\mathrm{FDG}$ PET revealed decrease of glucose metabolism in all treated thymic lymphomas, with subsequent increase of glucose metabolism (SUV $>3 \mathrm{~g} / \mathrm{mL}$ ) at days 20 and 24 of treatment (B).

${ }^{18}$ F-FDG PET Accurately Determines Response and Relapse in Systemic Chemotherapy of Trp53-/- Mice

For the treatment study, $13 \operatorname{Trp} 53^{-/-}$mice were serially scanned; 6 of these developed thymic SUVs exceeding $3 \mathrm{~g} /$ $\mathrm{mL}$ without developing additional malignancies (Fig. 5A).
These mice were scanned and treated intraperitoneally with $60 \mathrm{mg}$ of gemcitabine per kilogram every $4 \mathrm{~d}$ and were sacrificed at 12-24 d after the initialization of treatment. The treatment was generally well tolerated; no signs of toxicity or weight loss during treatment were observed 
(mean weight: day 0, $27.3 \pm 4.9 \mathrm{~g}$; day 12, $27.5 \pm 4.3 \mathrm{~g}$ ). Gemcitabine treatment resulted in complete remissions at days 12 and $16(n=3)$ and local recurrences under therapy at days 20 and 24 of treatment $(n=3)$, as verified by histology (Fig. 5B). Accordingly, treatment monitoring with ${ }^{18}$ F-FDG PET revealed a decrease of glucose metabolism in all treated thymic lymphomas (SUV $<3 \mathrm{~g} / \mathrm{mL}$ ), with subsequent increase of glucose metabolism (SUV $>$ $3 \mathrm{~g} / \mathrm{mL}$ ) at days 20 and 24 of treatment.

\section{DISCUSSION}

This study demonstrates that functional PET with ${ }^{18} \mathrm{~F}$ FDG on a dedicated small-animal scanner can be used to follow the development and treatment-induced metabolic changes of thymic lymphomas in $\operatorname{Trp} 53^{-1-}$ mice. ${ }^{18} \mathrm{~F}-$ FDG PET was able to assess the onset of thymic lymphomas, provide a readout of the proliferation fraction, and monitor response and relapse after systemic chemotherapy in $\operatorname{Trp} 53^{-1-}$ mice. These findings facilitate intervention studies for the p53 knockout and possibly other transgenic cancer-predisposed mouse models.

\section{${ }^{18}$ F-FDG PET as Readout of Tumor Biology in Trp53 ${ }^{-1-}$ Mice}

In Trp53 $3^{+/+}$mice, serial ${ }^{18} \mathrm{~F}-\mathrm{FDG}$ PET enabled the study of the time course of physiologic changes in thymus metabolism of p53 wild-type mice. Decreasing glucose metabolism was found around week 16, consistent with the time of onset of thymic involution (29). When compared with wildtype mice, Trp53-/- mice with histologically excluded lymphomas showed elevated thymic glucose metabolism. This result may be due to the fact that loss of $p 53$ function can change the energy source in cells from respiratory pathways to glycolysis $(24,30,31)$. With the SUV threshold of $3 \mathrm{~g} / \mathrm{mL}$ established in this study, these metabolic measurements can be used as a diagnostic test with a high sensitivity and specificity for detecting lymphoma development in $\operatorname{Trp} 53^{-1-}$ mice.

To be useful for the preclinical evaluations of drugs and other therapeutics, any method for assessing lesions should also provide the ability to characterize biologic features of individual lesions. This study demonstrates that in Trp53-1mice the level of tumor ${ }^{18} \mathrm{~F}$-FDG uptake is highly correlated with the proliferation of individual lesions. However, it has to be emphasized that isoflurane has been shown to increase serum glucose levels during anesthesia $(32,33)$, as is reflected by an increase myocardial ${ }^{18} \mathrm{~F}-\mathrm{FDG}$ uptake. This increase might pose difficulties during quantification of lesions near the heart, such as the thymus, by spillover due to partial-volume effect. Furthermore, part of the increase in SUVs over time might be due to tumor growth and a resulting decrease in partial-volume effects.

A further capacity of serial PET demonstrated by this study is the whole-body scan that is able to detect and monitor further lesions in, for example, the spleen. Additionally, malignancies other than lymphomas frequently develop in $\operatorname{Trp53}{ }^{-/-}$mice. Here, ${ }^{18} \mathrm{~F}-\mathrm{FDG}$ PET can reduce the number of mice needed for an intervention study, because these additional lesions can be detected and the respective mice can be excluded from experiments focusing on lymphoma development and progression.

\section{${ }^{18}$ F-FDG PET for Treatment Monitoring in Trp53-1- Mice}

A gemcitabine treatment model in $\operatorname{Trp53}{ }^{-/-}$mice was used to validate the use of ${ }^{18} \mathrm{~F}$-FDG PET for assessing response to systemic chemotherapy. Gemcitabine is a pyrimidine analog that has shown promising results, especially in pretreated patients with Hodgkin lymphoma and non-Hodgkin lymphoma (34). The favorable toxicity profile of gemcitabine allows the development of combination regimens with other cytotoxic drugs (35). This study revealed that treatment with $60 \mathrm{mg}$ of gemcitabine per kilogram every $4 \mathrm{~d}$ in Trp53 ${ }^{-1-}$ mice reproducibly induces treatment response, with subsequent relapse under therapy, each accurately assessed by ${ }^{18}$ F-FDG PET. Moreover, the SUV threshold of $3 \mathrm{~g} / \mathrm{mL}$ for predicting the presence of thymic lymphomas, as derived from the diagnostic part of this study, was validated to indicate tumor relapse during therapy.

These studies illustrate the value of ${ }^{18} \mathrm{~F}-\mathrm{FDG}$ PET of alterations in glycolysis in identifying lymphomas and associated malignancies during their development throughout tissues of the body and assessment of therapeutic responses using $\operatorname{Tr} p 53^{-/-}$mice. The longitudinal studies in which each animal serves as it own control increase the statistical power for detecting changes in glycolysis and reduce the number of animals needed for a given level of significance per study objective.

The unique importance of the tumor suppressor gene Trp53 in human cancer has prompted significant effort in the development of several strategies for modulating p53 in cancer cells. These therapies include small molecules and peptides that restore normal p53 function in tumors (36) and gene therapy approaches for eliminating mutant $p 53$ (37) or delivery of wild-type $p 53$ directly into tumor cells (38). So far, clinical trials show limited therapeutic benefits, despite promising preclinical results (39-41). These clinical results clearly demonstrate that further in vivo studies are required for improving $p 53$-targeting cancer therapy. In this context, orthotopic tumor models remain important because they, in particular, enable the site-specific dependence of the treatment and testing principles of early intervention therapies to be analyzed (42).

\section{CONCLUSION}

Our study seems to be the first study to demonstrate that longitudinal noninvasive small-animal PET allows for the precise and efficient analysis of lymphoma growth and therapy response and detection of further involved organs in the Trp53 ${ }^{-/-}$mouse model. Thereby, ${ }^{18}$ F-FDG PET has the potential to become a valuable tool for refining of $p 53$ targeting cancer therapy. 


\section{ACKNOWLEDGMENTS}

This study was supported in part by funds from the University Basel and the Swiss National Science Foundation.

\section{REFERENCES}

1. Frese KK, Tuveson DA. Maximizing mouse cancer models. Nat Rev Cancer. 2007; 7:645-658

2. Carver BS, Pandolfi PP. Mouse modeling in oncologic preclinical and translational research. Clin Cancer Res. 2006;12:5305-5311.

3. Kirsch DG, Kastan MB. Tumor-suppressor p53: implications for tumor development and prognosis. J Clin Oncol. 1998;16:3158-3168.

4. Imamura J, Miyoshi I, Koeffler HP. p53 in hematologic malignancies. Blood. 1994;84:2412-2421.

5. Vogelstein B, Lane D, Levine AJ. Surfing the p53 network. Nature. 2000; 408:307-310.

6. Sander CA, Yano T, Clark HM, et al. p53 mutation is associated with progression in follicular lymphomas. Blood. 1993;82:1994-2004.

7. Lo Coco F, Gaidano G, Louie DC, Offit K, Chaganti RS, Dalla-Favera R. p53 mutations are associated with histologic transformation of follicular lymphoma. Blood. 1993;82:2289-2295.

8. Du M, Peng H, Singh N, Isaacson PG, Pan L. The accumulation of p53 abnormalities is associated with progression of mucosa-associated lymphoid tissue lymphoma. Blood. 1995;86:4587-4593.

9. Hernandez L, Fest T, Cazorla M, et al. p53 gene mutations and protein overexpression are associated with aggressive variants of mantle cell lymphomas. Blood. 1996;87:3351-3359.

10. Sanchez-Beato M, Sanchez-Aguilera A, Piris MA. Cell cycle deregulation in B-cell lymphomas. Blood. 2003;101:1220-1235.

11. Nieder C, Petersen S, Petersen C, Thames HD. The challenge of p53 as prognostic and predictive factor in Hodgkin's or non-Hodgkin's lymphoma. Ann Hematol. 2001;80:2-8.

12. Donehower LA, Harvey M, Slagle BL, et al. Mice deficient for p53 are developmentally normal but susceptible to spontaneous tumours. Nature. 1992;356:215-221.

13. Tsukada T, Tomooka Y, Takai S, et al. Enhanced proliferative potential in culture of cells from p53-deficient mice. Oncogene. 1993;8:3313-3322.

14. Jacks T, Remington L, Williams BO, et al. Tumor spectrum analysis in p53mutant mice. Curr Biol. 1994;4:1-7.

15. Purdie CA, Harrison DJ, Peter A, et al. Tumour incidence, spectrum and ploidy in mice with a large deletion in the p53 gene. Oncogene. 1994;9: 603-609.

16. Attardi LD, Donehower LA. Probing p53 biological functions through the use of genetically engineered mouse models. Mutat Res. 2005;576:4-21.

17. Strasser A, Harris AW, Jacks T, Cory S. DNA damage can induce apoptosis in proliferating lymphoid cells via p53-independent mechanisms inhibitable by Bcl-2. Cell. 1994;79:329-339.

18. Difilippantonio MJ, Zhu J, Chen HT, et al. DNA repair protein Ku80 suppresses chromosomal aberrations and malignant transformation. Nature. 2000;404: 510-514.

19. Sablina AA, Budanov AV, Ilyinskaya GV, Agapova LS, Kravchenko JE, Chumakov PM. The antioxidant function of the p53 tumor suppressor. Nat Med. 2005;11:1306-1313.

20. Wloga EH, Criniti V, Yamasaki L, Bronson RT. Lymphomagenesis and femalespecific lethality in p53-deficient mice occur independently of E2f1. Nat Cell Biol. 2004;6:565-567, author reply 567-568.
21. Seam P, Juweid ME, Cheson BD. The role of FDG-PET scans in patients with lymphoma. Blood. 2007;110:3507-3516.

22. Terasawa T, Lau J, Bardet S, et al. Fluorine-18-fluorodeoxyglucose positron emission tomography for interim response assessment of advanced-stage Hodgkin's lymphoma and diffuse large B-cell lymphoma: a systematic review. J Clin Oncol. 2009;27:1906-1914.

23. Samper E, Morgado L, Estrada JC, et al. Increase in mitochondrial biogenesis, oxidative stress, and glycolysis in murine lymphomas. Free Radic Biol Med. 2009;46:387-396.

24. Kawauchi K, Araki K, Tobiume K, Tanaka N. p53 regulates glucose metabolism through an IKK-NF-кB pathway and inhibits cell transformation. Nat Cell Biol. 2008;10:611-618.

25. Abbey CK, Borowsky AD, McGoldrick ET, et al. In vivo positron-emission tomography imaging of progression and transformation in a mouse model of mammary neoplasia. Proc Natl Acad Sci USA. 2004;101:11438-11443.

26. Guide for the Care and Use of Laboratory Animals. Bethesda, MD: National Institutes of Health; 1985. NIH publication 85-23.

27. Suckow C, Kuntner C, Chow P, Silverman R, Chatziioannou A, Stout D. Multimodality rodent imaging chambers for use under barrier conditions with gas anesthesia. Mol Imaging Biol. 2009;11:100-106.

28. Loening AM, Gambhir SS. AMIDE: a free software tool for multimodality medical image analysis. Mol Imaging. 2003;2:131-137.

29. Hsu HC, Zhang HG, Li L, et al. Age-related thymic involution in C57BL/6 J x $\mathrm{DBA} / 2 \mathrm{~J}$ recombinant-inbred mice maps to mouse chromosomes 9 and 10 . Genes Immun. 2003;4:402-410.

30. Bensaad K, Vousden KH. p53: new roles in metabolism. Trends Cell Biol. 2007; 17:286-291.

31. Kawauchi K, Araki K, Tobiume K, Tanaka N. Loss of p53 enhances catalytic activity of IKK $\beta$ through $\mathrm{O}$-linked $\beta$-N-acetyl glucosamine modification. Proc Natl Acad Sci USA. 2009;106:3431-3436.

32. Flores JE, McFarland LM, Vanderbilt A, Ogasawara AK, Williams SP. The effects of anesthetic agent and carrier gas on blood glucose and tissue uptake in mice undergoing dynamic FDG-PET imaging: sevoflurane and isoflurane compared in air and in oxygen. Mol Imaging Biol. 2008;10:192-200.

33. Woo SK, Lee TS, Kim KM, et al. Anesthesia condition for ${ }^{18} \mathrm{~F}-\mathrm{FDG}$ imaging of lung metastasis tumors using small animal PET. Nucl Med Biol. 2008;35: 143-150.

34. Oki Y, Younes A. Current role of gemcitabine in the treatment of Hodgkin lymphoma. Leuk Lymphoma. 2008;49:883-889.

35. Chau I, Watkins D, Cunningham D. Gemcitabine and its combinations in the treatment of malignant lymphoma. Clin Lymphoma. 2002;3:97-104

36. Bullock AN, Fersht AR. Rescuing the function of mutant p53. Nat Rev Cancer. 2001;1:68-76.

37. Rogulski KR, Freytag SO, Zhang K, et al. In vivo antitumor activity of ONYX015 is influenced by p53 status and is augmented by radiotherapy. Cancer Res. 2000;60:1193-1196.

38. Horowitz J. Adenovirus-mediated p53 gene therapy: overview of preclinical studies and potential clinical applications. Curr Opin Mol Ther. 1999;1: 500-509.

39. Shimada H, Matsubara H, Shiratori $T$, et al. Phase I/II adenoviral p53 gene therapy for chemoradiation resistant advanced esophageal squamous cell carcinoma. Cancer Sci. 2006;97:554-561

40. Wolf JK, Bodurka DC, Gano JB, et al. A phase I study of Adp53 (INGN 201; ADVEXIN) for patients with platinum- and paclitaxel-resistant epithelial ovarian cancer. Gynecol Oncol. 2004;94:442-448.

41. Zeimet AG, Marth C. Why did p53 gene therapy fail in ovarian cancer? Lancet Oncol. 2003;4:415-422.

42. Killion JJ, Radinsky R, Fidler IJ. Orthotopic models are necessary to predict therapy of transplantable tumors in mice. Cancer Metastasis Rev. 1998;17:279-284. 